\title{
The Ancient Architecture We Chased together in Those Years
}

\author{
Liu Yanpeng \\ Hengshui High School, Hengshui, Hebei 053000, China
}

Keywords: elective course; ancient architecture; history

\begin{abstract}
The Outline of the National Medium- and Long-Term Education Reform and Development Plan (2010-2020) states that it is necessary to create conditions to offer a variety of elective courses to provide students with more choices and to promote students' comprehensive and individual development. During the process of education and teaching, I also actively carried out the exploration of school-based elective courses. In fact, the reason for the initial elective course was found in the process of communication with students. The students did not fully understand the ancient buildings in many hometowns around them. Such a classmate who talks about his love for his hometown and his love for the country makes him worried. Since I used to visit ancient buildings frequently, I started a positive attempt. To be more precise, it was a dream, a dream that I have been following, so I have an elective course that I have opened - "The years, Chinese ancient buildings that we chased together.
\end{abstract}

With this dream, I opened this school-based elective course and started my dream-seeking road.

Chasing the surface - from the experience, the real visible

Chasing its insights - knowledge mosaic, connected into pieces

Chasing its embedded - style change, learning the main line

Chasing his thoughts - history reappears, ancient is today

Chasing his love - reading thousands of volumes, field drill

\section{Chasing its surface - from the experience, the real visible}

Because the flexibility of elective courses is not limited to text books, I hope to bring more intuitive feelings to the students in the classroom. In order to combine the theory with the reality and enhance the attraction of ancient architecture, I use my own in the classroom design. As far as the background of Chinese ancient architecture is concerned, each lesson tells a Chinese ancient architecture, interspersed with ancient architectural knowledge, human knowledge and stories behind ancient buildings. I did not expect such a classroom to be greatly welcomed by students.

Speaking of after the enclosures of Prince Gong Mansion, I would say that it is commonly known as "the ninety-nine and a half". It is a veritable "Cangbao House". It tells the Beijing Lama Temple and will show it to the students in the corner pavilion of the Lama Temple. The inscription "Lama said" uses examples to prove the Qing Dynasty's true attitude towards Tibetan Buddhism. When I talked about the South Luogu Lane, I will tell my classmates what is "being matched for mariage" through the decoration in front of the door, and tell the story of the alley. The former residence of celebrities tells the vivid stories of these celebrities in this alley.

Such a lively example has greatly attracted the interest of the students. The original ancient buildings can also live, and the students' interest in ancient buildings has greatly increased. Moreover, during the field trip, it was found that the communication with the local people also promoted a more intuitive understanding of ancient architecture.

\section{Chasing its insights - knowledge mosaic, connected into pieces}

Interest is the best teacher, but when you are preparing for lessons, it is not enough to find out that it is not enough because Chinese ancient architecture contains a lot of knowledge. If you want to systematically explain, you must systematically study. 
First of all, from the most basic point of view, I read a lot of relevant content related to the building before each inspection. After returning back, I summarize it in time, and sometimes I will buy some books related to this ancient building to be more systematic to understand, so what I am talking about is a good combination of books and reality. In order to better teach the knowledge, I read a lot of related professional books. It is really difficult for me to read these professional books. However, the interest is really the best teacher. Sublimation, "Book of Diverse Crafts" "exploitation of the works of nature ", "art of garden-building", "Gongcheng zuofa zeli", "Qing's Construction", "Lin Huiyin's Building-teaching", " Construction method of the original", "Chinese Ancient Building Construction Technology", "Chinese Architectural History" "Chinese Architecture Types and Structures", etc., through such deep learning, the teaching ideas of their own are more and more clear.

\section{Chasing its embedded - style change, humanistic main line}

When talking about ancient architecture, I often use a specific example to expand and let me know the relevant architectural knowledge, so that the students have a deeper understanding of the building itself and related content.

The blue sky and white clouds make the background, the three layers of glazed tiles are layered in, and the golden treasures go straight into the sky. This is the Hall of Prayer for Good Harvests in Beijing. When I talked about the Hall of Prayer for Good Harvests, I highlighted the pillars of the Hall of Prayer. There are thirty-six pillars in the Hall of Prayer, and the four pillars in the innermost layer are called posts, representing the four seasons; the twelve pillars in the middle layer are called the golden pillars, representing twelve months in a year; the twelve outermost layers The pillar, called the mast, represents twelve one of the 12 two-hour periods of the day of the day; twelve gold pillars plus twelve pillars equal twenty-four, representing twenty-four stars; twenty-four plus four dragon pillars equal to twenty Eight, representing twenty-eight stars; twenty-eight plus the top eight pillars of the guilt is equal to thirty-six, equal to thirty-six days. In this way, everyone explained that the students not only learned about the architectural pattern, but also let the students understand that the humanity of the building has a deeper understanding.

When I talk about the Forbidden City, I will specifically talk about the beasts on the roof, because in the usual buildings, I will see the ancient buildings with ridged beasts. They are more or less different, but the number of them represents the rank and number. The higher the level, the more the 10 sacred beasts on the Palace Museum and the temple represent the highest level of architecture, unique, representing the supremacy of the imperial power. These 10 swan beasts also have jingles "one dragon, two phoenix three lions, seahorse Tianma six carp, Lion haetae, nine bullfights, and finally like a monkey", each swan beast also has its own story, and The "five ridges and six beasts" we usually call are also from this. Then I will show the students the ridges on different ridges. After seeing the students, they will have a deeper understanding of the ridges.

Through such explanations, the students were deeply impressed by the wisdom of the ancients. I and my classmates also created a spark of thinking collision in the world of ancient architecture. When we studied at a certain point, we found that we actually connect in series to one of our architectural worlds.

\section{Retroactivity--Bring history to life and advise nowadays}

Architecture is a history of solidification. Every Chinese ancient building has their own one or more historical stories which are often thought-provoked and intrigued by people.

Most of the students will think back the previous imperial examinations when they talk about the college entrance examination. However, a real understanding which bases on the imperial examinations place will give us a deeper feeling. Jiangnan Gongyuan is the largest one in Chinese ancient times. For candidates, it is not only a test place for candidates but also a place to realize their own life. For the country, it will provide talent for the government. Less than 1.5 square meters and two table boards were used to answer questions during the day and rest at night, which is 
named Number of Houses. In the period of Tongzhi, the number of this room even reached up to 20,644. Reminding the candidates of past and now, how similar they are! In such place, every candidate who eager to realize his dream of "turning to Tianshanglang, squatting to the heavenly court" read and wrote and some of them had become the pillar of the notion. It is no doubt that the imperial examination and the college entrance examination need to be perfected in many aspects, but a lot of people still have change their fates through this way. Thanks to these ancient buildings for giving people the best testimony.

Time like a ruthless knife changes the look of youth. However, such one by one lively story has left a deep impression on people and strengthen their determination to protect the Chinese ancient architecture.

\section{Explore the change--Colorful ancient buildings}

The famous architect Liang Sicheng used modern scientific technology to survey and map many Chinese valuable ancient buildings, then combined with historical documents and interviews of old craftsmen, finally published numerous books, investigation reports and academic papers such as The Qing Dynasty Construction Case, Chinese Architecture History, Chinese Sculpture History, Jianxian Dule Temple Guanyin Pavilion and Shanmen Kao, Zhengding Ancient Building Investigation Report, Wutaishan Foguang Temple Architecture during his more than ten years extremely difficult conditions of building school. Thus he laid a deep foundation for the research and protection of Chinese architecture.

However, although I can't be as academic as Mr. Liang Sicheng, I also feel, understand and then spread ancient buildings through the field test site. Moreover I have opened a related courses base on my own certain accumulations, such as Younan Luguxiang - Beijing Hutong Culture, Exploring Qing Tombs - Emperor Mausoleum System, Forbidden City Forbidden City - Royal Palace Pattern, Golden Lama Temple - Tibetan Buddhist Temple, Zhengding Longxing Temple - -mortise joint Architectural Art, Tianjin Fifth Avenue--History of the Rise and Fall of the Concession, Yuqiu Prayer Hall - Sacrifice Heaven and Gu Valley Tradition, Xi'an Ancient City Wall - City Wall Construction Protection, Guanjiang Nangong Academy - Ming and Qing Dynasties Examination, Feeling Yuanmingyuan - Landscape Design, Shangjingshan Park - Central Axis Symmetry Thought, Millennium Zhaozhou Bridge - Ancient Bridge Construction, Zhi Li Governor's Office - Official House Tuen Mun Layout.

It can be said that every course is saturated with sweat. I hope that not only to plant a seed, but also expect the seed will grow up more powerful, fuller, and touch the children heart more.

\section{Pursue perfection--Unity of knowledge and practice}

The most gratifying thing is to see the changes of my students. Through the series of courses, I have been able to feel that my classmates are already falling in love with the Chinese ancient architecture like me deeply, and we have started more exploration together.

The Outline of the National Medium- and Long-Term Education Reform and Development Plan (2010-2020) states that cultural communication should be actively promoted, excellent traditional culture should be promoted, and advanced culture should be developed. While Chinese ancient architecture is a good carrier of Chinese traditional culture, what I have to do is to better spread traditional culture through such a carrier. Every child is the pillar of nation in future. The talents cultivated today will be the main force to achieve the goal of the second century. The tradition needs to be continued, and education needs innovation, culture needs carrier. As a teacher, I feel the mission and will continue to love the Chinese ancient buildings. There is a kind of education called love, and there is an education called not forgetting the root. There is an education called inheritance extension. There is an education called returning to the truth. This is the year we are together. Chasing the ancient Chinese architecture, I am willing to continue to contribute my own little power to push the growth of the children and improve the development of China! 


\section{References}

[1] Xie Zihan, on the protection and renewal design of historical buildings from the perspective of phenomenology, Chinese and foreign architecture [J] 2018

[2] Wu Liangxuan. Looking forward to the future of architecture at the turn of the century. Journal of Architecture. Beijing: Chinese Architecture Society, 1999, (8)

[3] Wang Zongnian. Architectural Space Art and Technology [M]. Chengdu: Chengdu University of Science and Technology Press, 1987. 121.

[4] Jiang Junhao. The value of traditional decorative symbols and its application in architectural design. Urban construction [J]. September 2009 